$\underline{\text { Research paper }}$

\title{
Proportion of superficial fungal infections among members of the cleaning staff at the University of Sri Jayewardenepura
}

\author{
WPSSS Perera ${ }^{1}$, RSR Rajakulasooriya ${ }^{1}$, MM Weerasekera ${ }^{1}$, J Kottahachchi ${ }^{1}$, \\ TDCP Gunasekera ${ }^{1}$, LBAE Bogahawatta ${ }^{1}$, SSN Fernando ${ }^{1}$ \\ Sri Lankan Journal of Infectious Diseases 2014 Vol.4 (1):38-47 \\ DOI: http://dx.doi.org/10.4038/sljid.v4i1.6061
}

Key words: Superficial fungal infections, cleaning staff

\begin{abstract}
Introduction

Superficial fungal infections (SFIs) are infections of the keratinous tissue caused by dermatophytes, yeasts and non-dermatophyte fungi. Cleaning staff are identified as a risk category for SFI as they are frequently exposed to a moist environment.
\end{abstract}

\section{Objective}

To determine the proportion of infection, knowledge, attitudes, practices and risk factors for superficial fungal infections among members of the cleaning staff at the University of Sri Jayewardenepura

\section{Methods}

Eighty two cleaning staff members were included in the study. Clinical examination for SFIs was done by a Clinical Microbiologist and sample processing was carried out at the Department of Microbiology between May to October 2012. Laboratory identification of the fungal organisms was done using direct microscopy $(10 \% \mathrm{KOH})$ followed by culture on Sabouraud Dextrose Agar with and without chloramphenicol and cycloheximide. Morphological and physiological methods were used to speciate the isolated fungi. An interviewer administered questionnaire was used to assess the knowledge, attitudes and practices (KAPs) on SFIs. Risk factors such as age, occupation, prolonged contact with water, detergents and soil were analyzed. Scores were allocated for each answer and the total scores calculated for each category of KAPs.

\section{Results}

Forty two out of 82 participants $(50 \%)$ had SFIs. Out of the 56 clinically suspected cases, 76 specimens were collected from different infected sites. Four skin scrapings were identified as

\footnotetext{
${ }^{1}$ Department of Microbiology, Faculty of Medical Sciences, University of Sri Jayewardenepura, Nugegoda, Sri Lanka

Address for correspondence: Dr J. Kottahachchi, Faculty of Medical Sciences, University of Sri Jayewardenepura, Nugegoda, Sri Lanka E-mail: jananiekottahachchi@yahoo.com ; Tel.no: +94772987942
} 
Malassezia furfur by direct smear. Out of 57 scrapings and nail clippings, 45 (79\%) were $\mathrm{KOH}$ positive and twelve $(21 \%)$ negative by direct smear. Out of direct smear positive specimens, only 28 were culture positive while 17 were culture negative. Aspergillus niger was the commonest organism isolated from these specimens (20) followed by the non albicans candida spp. (7), Candida albicans (2), dermatiaceous fungi (7), Malassezia furfur (4), Fusarium spp. (3) and dermatophyte species. Multiple fungal species were isolated in 4 specimens.

Our study population had a satisfactory level of knowledge (58\%) while $49 \%$ had good attitudes, and $58 \%$ were shown to have a satisfactory level of adhering to safety practices. Further, there was no statistically significant relationship between the risk factors assessed and SFIs.

\section{Conclusion}

Aspergillus niger was the commonest pathogen causing SFIs in the study group. Although participants have a satisfactory level of knowledge, attitudes and practices towards SFIs, regular examination of this population is recommended because they are at high risk for SFIs.

\section{Introduction}

As a country with a high level of humidity and dusty environment, the Sri Lankan population is at high risk of getting superficial fungal infections (SFI). SFIs are a burden to society and negatively affect personality and self-esteem and may lead to many physical, psychosocial and occupational problems by changing the quality of life of the affected person.

Limited research has been published in Sri Lanka with regard to SFIs, with most studies based on candida infections. ${ }^{1}$ A very low prevalence of tinea capitis $(3.4 \%)$ has been reported among SFI cases during the period between 1978 - 1987 in Sri Lanka. ${ }^{2}$ A recent study done among type 2 diabetic patients in Sri Lanka had found a higher proportion of SFIs among this population and Aspergillus niger was found to be the commonest pathogen. ${ }^{3}$

Although the main causative agents of SFIs are dermatophytes (ring worm), infections with yeast (Candida species) and non dermatophytes are also reported with variations of climate, geographical location and individuality. ${ }^{4,5,6}$

Occupation, environmental conditions and health status are important predisposing factors for superficial fungal infections. Members of the cleaning staff are exposed to contact with water and a dusty environment during their work related activities. However there is no published literature on occupation related SFIs in Sri Lanka. In addition, the cleaning staff do not wear protective equipment (gloves, or sometimes even footwear) while working. Therefore they are more prone to develop superficial fungal infections.

It is also very important to assess knowledge about the infection, its prevention and treatment, as well as attitudes and practices related to SFIs among the cleaning staff in order to get a better understanding of infection in this group. The outcome of this study will be beneficial for initiating treatment, promoting awareness and thereby preventing SFIs in this study population and achieving higher work productivity. The current study was designed to determine the 
proportion of cleaning staff with SFI and its aetiology and risk factors, and to evaluate knowledge, attitude and practices of this group with regard to this infection.

\section{Methodology}

The study was a cross sectional study carried out at the University of Sri Jayewardenepura. Ethical clearance for the study was obtained from the Ethical Review Committee, University of Sri Jayewardenepura. Eighty two members of the cleaning staff were included. Written informed consent was obtained from all participants. An interviewer administered questionnaire was filled and the clinical examination for SFIs was done by a Clinical Microbiologist. Specimens such as nail clippings, skin scrapings and swabs were collected using the standard protocol for investigations.

Laboratory investigations were performed in the Department of Microbiology at University of Sri Jayewardenepura. Direct microscopy was done using $10 \% \mathrm{KOH}$, and the specimens were inoculated on Sabouraud Dextrose Agar with and without chloramphenicol and cycloheximide. Gram stain and lactophenol cotton blue tease mounts were used for identification. Yeast species were subjected to germ tube test while filamentous fungi were further identified using slide culture.

\section{Interviewer administered questionnaire}

A pre-tested interviewer administered questionnaire was used to collect data on sociodemographic variables (age, sex, marital status, occupational types and education level), occupational history (work experience, type of work), knowledge, attitudes and practices regarding SFIs including personal hygiene (number of family members, use of soap and wiping of body) and infection types.

Collected data were categorized and scored based on variables that were to be analyzed. The work related activities were categorized into six groups based on their main activities during work hours; Group 1 - soil/waste handling, Group 2 - office cleaning, Group 3 - cleaning laboratory/toilets, Group 4 - soil/waste handling and office cleaning, Group 5 - office cleaning and laboratory/toilet cleaning and Group 6 - all activities.

The data for knowledge, attitudes and practices were obtained through a questionnaire. Each question was awarded a score of either five marks or zero. Volunteers who gave the correct answers to questions were given five marks and those who gave incorrect answers were given zero marks. In the case of multiple correct answers, those who gave more than $50 \%$ of correct answers were given five marks and the others who had not answered or gave $50 \%$ or more incorrect answers were allocated zero marks.

Statistical analysis - Laboratory investigation and questionnaire data were analyzed by calculating percentages. Demographic data were calculated and expressed as percentages. Chi square test was used for determination of the significant relationships between risk factors and presence of SFIs. The totals for knowledge, attitudes and practices for each study unit were calculated out of 35, 40 and 40 marks respectively. Hence the overall knowledge, attitudes and 
practices contained 115 marks. All marks were separately converted into a percentage and thereafter categorized as follows. Participants who scored more than seventy five percent $(>75 \%)$ marks were categorized as good, while $50-75 \%$ were satisfactory and $<50 \%$ were considered as unsatisfactory. Data was analyzed using SPSS software (version 16).

\section{Results}

Of the 82 participants, seventy two were females. Forty four (54\%) participants were between 40-60 years and comprised the majority. The mean age was 54 years. The majority of participants $(52 \%)$ had more than two years of work experience. All participants, except nine who never had a formal education (11\%), had at least primary education. Fifty five $(67 \%)$ participants were engaged in outdoor activities such as cleaning the garden, weeding and handling of office or domestic and garden waste.

There was no statistical significance between the different demographic variables with regard to SFIs. In this study group forty two (51\%) participants had SFIs.

Among the 42 confirmed SFI cases, 31 (74\%) were suffering from onychomycosis, five (12\%) had skin infections and one (2\%) had pityriasis versicolor infection. Five (12\%) participants showed mixed infections of onychomycosis, skin infections and pityriasis versicolor.

Table 1: Number and percentage of identified fungal species among infected individuals

\begin{tabular}{lcc}
\hline Etiological agents & $\begin{array}{c}\text { Number infected } \\
(42)\end{array}$ & $\begin{array}{c}\text { Percent } \\
(\%)\end{array}$ \\
\hline Aspergillus niger & 20 & 47.6 \\
Non- albicans Candida spp. & 8 & 19.5 \\
Dematiaceous fungi & 7 & 17.5 \\
Malassezia furfur & 4 & 9.5 \\
Fusarium spp. & 3 & 7.1 \\
Candida albicans & 2 & 4.8 \\
Other Aspergillus spp. & 2 & 4.8 \\
Trichophyton mentagrophytes & 1 & 2.4 \\
Trichophyton violaceum & 1 & 2.4 \\
Trichophyton tonsurans & 1 & 2.4 \\
Epidermophyton floccosum & 1 & 2.4 \\
\hline
\end{tabular}

Malassezia furfur was identified in 4 skin scrapings by direct smear. Out of 57 scrapings and nail clippings, $45(79 \%)$ were positive by direct smear and 12 (21\%) were negative. Of the direct smear negatives, $9(75 \%)$ were positive by culture. From the direct smear positive specimens, only 28 (62\%) were culture positive while the other $17(38 \%)$ were culture negative. Aspergillus niger was the predominant species isolated $(48 \%)$, followed by non albicans Candida spp (19\%), dermatiaceous fungi (17.5\%) and Malassezia furfur (9\%; Table1).

Risk factors for SFIs are shown in Table 2. Among the study group, $58 \%$ of participants $>50$ years of age had SFIs while only $38 \%$ of $<50$ years presented with the infection. Among all infected participants, 55\% were highly exposed to risk factors such as prolonged contact with water, detergent and soil. It was noted that $52 \%$ of infected participants had unsatisfactory safety practices and also that $56 \%$ of them had cleaning work associated with water for more than 2 hours per day. 
Table 2: Relationship between risk-factors and superficial fungal infections

\begin{tabular}{|c|c|c|c|c|c|c|}
\hline \multicolumn{2}{|c|}{ Variable } & \multirow{2}{*}{$\begin{array}{c}\begin{array}{c}\text { Subjects } \\
\text { with SFI } \\
(\%)\end{array} \\
37.9 \\
58.5\end{array}$} & \multirow{2}{*}{$\begin{array}{c}\begin{array}{c}\text { Subjects } \\
\text { without } \\
\text { SFI (\%) }\end{array} \\
62.1 \\
41.5\end{array}$} & \multirow{2}{*}{$\begin{array}{c}\begin{array}{c}\text { Chi- } \\
\text { square }\end{array} \\
3.171\end{array}$} & \multirow{2}{*}{$\begin{array}{l}\mathrm{d} f \\
1\end{array}$} & \multirow{2}{*}{\begin{tabular}{|c|} 
P value \\
0.075 (NS)
\end{tabular}} \\
\hline Age & $\begin{array}{l}<50 \text { years } \\
>50 \text { years }\end{array}$ & & & & & \\
\hline Education level & $\begin{array}{l}\text { With formal education } \\
\text { No formal education }\end{array}$ & $\begin{array}{l}53.4 \\
33.3\end{array}$ & $\begin{array}{l}46.6 \\
66.7\end{array}$ & 1.294 & 1 & $0.255(\mathrm{NS})$ \\
\hline $\begin{array}{l}\text { Level of } \\
\text { exposure to risk } \\
\text { agent/condition }\end{array}$ & $\begin{array}{l}\text { Highly exposed } \\
\text { Poorly exposed }\end{array}$ & $\begin{array}{l}55.2 \\
41.7\end{array}$ & $\begin{array}{l}44.8 \\
58.3\end{array}$ & 1.239 & 1 & $0.266(\mathrm{NS})$ \\
\hline $\begin{array}{l}\text { Use of safety } \\
\text { measures }\end{array}$ & $\begin{array}{l}\text { Satisfactory } \\
\text { Unsatisfactory }\end{array}$ & $\begin{array}{l}50.0 \\
51.9\end{array}$ & $\begin{array}{l}50.0 \\
48.1\end{array}$ & 0.025 & 1 & $0.874(\mathrm{NS})$ \\
\hline $\begin{array}{l}\text { Duration of wet } \\
\text { work per day }\end{array}$ & $\begin{array}{l}<2 \text { hours } \\
>2 \text { hours }\end{array}$ & $\begin{array}{l}48.0 \\
56.2\end{array}$ & $\begin{array}{l}52.0 \\
43.8\end{array}$ & 0.532 & 1 & $0.466(\mathrm{NS})$ \\
\hline
\end{tabular}

Table 3: Knowledge regarding superficial fungal infections

\begin{tabular}{llcc}
\hline \multicolumn{1}{c}{ Question } & & $\begin{array}{c}\text { Number } \\
(\mathrm{n}=82)\end{array}$ & $\begin{array}{c}\text { Percentage } \\
(\%)\end{array}$ \\
\hline Understanding what SFIs are & Yes * & 49 & 59.8 \\
& No & 33 & 40.2 \\
\hline Knowledge on possible sites of SFIs & Yes * & 50 & 61 \\
\hline Knowledge on predisposing disease/ & No & 32 & 39 \\
\hline conditions that predispose to SFIs & No $*$ & 24 & 29.3 \\
Knowledge on occupations at risk of SFIs & Yes * & 58 & 70.7 \\
& No & 32 & 63.4 \\
\hline Knowledge on mode of transmission & Yes * & 33 & 36.6 \\
\hline Knowledge on occupation related safety & Yes * & 37 & 40.2 \\
practices regarding SFIs & No & 45 & 54.9 \\
\hline Knowledge on personal safety practices & Yes * & 55 & 67.1 \\
against the SFIs & No & 27 & 32.9 \\
\hline
\end{tabular}


When knowledge, attitudes and practices were evaluated in the study group, no statistical significance was determined (Tables 3, 4, and 5). However certain interesting factors were observed in the study, such as satisfactory understanding about SFIs and their occurrence $(61 \%)$. We also observed that $71 \%$ were not aware of conditions that predispose to SFIs such as diabetes. Knowledge on how SFIs are transmitted and occupation related preventive practices were also poor among the study population as shown in Table 3 .

Table 4: Attitudes regarding superficial fungal infections

\begin{tabular}{|c|c|c|c|}
\hline \multicolumn{2}{|l|}{ Question } & $\begin{array}{c}\text { Number } \\
\mathbf{n}=\mathbf{8 2}\end{array}$ & $\begin{array}{c}\text { Percentage } \\
\%\end{array}$ \\
\hline \multirow{2}{*}{$\begin{array}{l}\text { SFIs can give rise to } \\
\text { adverse effects }\end{array}$} & Yes* & 42 & 51.2 \\
\hline & No & 40 & 48.8 \\
\hline \multirow{2}{*}{$\begin{array}{l}\text { I believe that we should } \\
\text { take medicines for SFIs }\end{array}$} & Yes* & 67 & 81.7 \\
\hline & No & 15 & 18.3 \\
\hline SFIs are caused by & Yes* & 42 & 51.2 \\
\hline frequent use of water & No & 40 & 48.8 \\
\hline \multirow{2}{*}{$\begin{array}{l}\text { SFIs are caused due to my } \\
\text { occupation }\end{array}$} & Yes* & 38 & 46.3 \\
\hline & No & 44 & 53.7 \\
\hline \multirow{2}{*}{$\begin{array}{l}\text { SFIs are caused due to } \\
\text { poor skin hygiene }\end{array}$} & Yes & 66 & 80.5 \\
\hline & No* & 16 & 19.5 \\
\hline \multirow[t]{2}{*}{ SFIs are caused by God } & Yes & 62 & 75.6 \\
\hline & No* & 20 & 24.4 \\
\hline \multirow{2}{*}{$\begin{array}{l}\text { I believe that SFIs heal } \\
\text { itself }\end{array}$} & Yes & 59 & 46.3 \\
\hline & No* & 23 & 53.7 \\
\hline \multirow{2}{*}{$\begin{array}{l}\text { SFIs are unavoidable and } \\
\text { it's a normal condition }\end{array}$} & Yes & 38 & 46.3 \\
\hline & No* & 44 & 53.7 \\
\hline
\end{tabular}

The study population's attitudes regarding SFIs were satisfactory. Importantly $82 \%$ believed that medical treatment should be obtained for SFIs. However $76 \%$ believed that SFIs are caused by God (Table 4). Many (73\%) said that they would take western medicine as treatment for SFIs.

Poor level of safety practices were seen among the study group. Very few claimed to use safety equipment (protective

gloves, boots and clothes) during working hours (Table 5). Further, a majority (72\%) of cleaners were not given proper instructions on safety precautions when handling water, chemicals etc.

A satisfactory level of knowledge was seen in $58 \%$ of the study population, with good attitudes in $49 \%$ and satisfactory level of practice in $58 \%$.

\section{Discussion}

Being a country with a tropical climate, the prevalence of SFIs in clinical practice is high in Sri Lanka despite the lack of published evidence. Hence SFIs among a group of people who were at risk due to their occupational exposure was studied. Aspergillus niger was the most common causative pathogen which was a new finding in the study. Comparison of study data with previous data was not possible due to a lack of studies on SFI in a similar study population or in the general population in Sri Lanka. However several studies done in other parts of the world had reported similar results of high prevalence. In a study done in Iran, the prevalence of SFIs among different occupations showed that $46.1 \%$ of gardeners, $30.8 \%$ of sanitary workers and $23.1 \%$ of dishwashers and one cook had SFIs. ${ }^{7}$ Most of the volunteers in our study population were engaged in gardening and we found a higher proportion $(30.5 \%)$ of SFIs among them.

A. niger is mainly a saprophytic fungus which is found in the soil and was the commonest pathogen $(48 \%)$ causing SFIs in the study. It is a pathogen causing onychomycosis and more 
common among those engaged in gardening or frequent contact with soil. ${ }^{8}$ The volunteers in this study were routinely exposed to water, dust and soil. Fifty five (67\%) participants from our study group were engaged mainly in outdoor activities such as weeding, collecting garbage and landscaping. Several studies have also reported cases with onychomycosis due to exposure to Aspergillus spp. ${ }^{9,10}$

Table 5: practices regarding superficial fungal infections

\begin{tabular}{|c|c|c|c|}
\hline Question & & Number & Percent \\
\hline \multirow{7}{*}{$\begin{array}{l}\text { What are the exposing agents/ conditions } \\
\text { during your occupation? }\end{array}$} & Water & 5 & 6.1 \\
\hline & $\begin{array}{l}\text { Organic substances } \\
\text { (Disinfectant/Detergent/Soap) }\end{array}$ & 3 & 3.7 \\
\hline & Soil/Garbage & 22 & 26.8 \\
\hline & Water and organic substances & 20 & 24.4 \\
\hline & Water and soil/garbage & 6 & 7.3 \\
\hline & Soil/garbage and organic substances & 7 & 8.5 \\
\hline & Water, organic substances and soil/garbage & 19 & 23.2 \\
\hline \multirow{8}{*}{$\begin{array}{l}\text { What are the safety measures that you have } \\
\text { taken during your working time? }\end{array}$} & Safety Gloves & 8 & 9.8 \\
\hline & Safety boots & 17 & 20.7 \\
\hline & Safety clothes & 10 & 12.2 \\
\hline & Not use anything & 19 & 23.2 \\
\hline & Use safety gloves/clothes/boots & 8 & 9.8 \\
\hline & Use safety gloves/boots & 11 & 13.4 \\
\hline & Use safety gloves/clothes & 3 & 3.7 \\
\hline & Use safety boots/clothes & 6 & 7.3 \\
\hline \multirow{2}{*}{$\begin{array}{l}\text { Have you been instructed on using Question (1) } \\
\text { agents? }\end{array}$} & Yes & 23 & 28.0 \\
\hline & No & 59 & 72.0 \\
\hline \multirow{5}{*}{$\begin{array}{l}\text { What is the mode of treatment that you will be } \\
\text { taking, if you have any SFIs? }\end{array}$} & Ayurvedic medicine & 7 & 8.5 \\
\hline & Self -treatment & 3 & 3.7 \\
\hline & Western medicine & 60 & 73.2 \\
\hline & Don't use any treatment & 9 & 11.0 \\
\hline & Ayurvedic and self -treatment & 3 & 3.7 \\
\hline \multirow{2}{*}{$\begin{array}{l}\text { Did you observe having any SFIs during your } \\
\text { current working period? }\end{array}$} & Yes & 24 & 23 \\
\hline & No & 58 & 70.7 \\
\hline \multirow{2}{*}{$\begin{array}{l}\text { Do you dry your body parts after cleaning } \\
\text { them? }\end{array}$} & Yes & 74 & 90.2 \\
\hline & No & 8 & 9.8 \\
\hline \multirow{2}{*}{$\begin{array}{l}\text { Do you share your clothes between friends or } \\
\text { family members? }\end{array}$} & Yes & 7 & 8.5 \\
\hline & No & 75 & 91.5 \\
\hline \multirow{3}{*}{$\begin{array}{l}\text { How many hours (Average) do you take for } \\
\text { work related activity per day? }\end{array}$} & $<30 \mathrm{~min}$ & 17 & 20.7 \\
\hline & $30-120 \mathrm{~min}$ & 33 & 40.2 \\
\hline & $>120 \mathrm{~min}$ & 32 & 39.0 \\
\hline
\end{tabular}

Non albicans Candida species (19\%) were found to be the second most common pathogen causing SFIs. Although Candida albicans is the most common yeast causing SFIs, according to Martínez (2010), the involvement of non albicans Candida species such as $C$. tropicalis, $C$. parapsilosis, $C$. dubliniensis, $C$. famata, and $C$. lipolytica is also known to be increasing. ${ }^{11}$

The most common SFI was onychomycosis $(74 \%)$ and these results are in accordance with the other available literature. ${ }^{12}$ The second commonest SFI was skin infections. Mixed infections were seen in five of the volunteers having onychomycosis with skin infections, onychomycosis 
with pityriasis versicolor and skin infections with pityriasis versicolor. The prevalence of tinea capitis was very low in the current study.

Although forty five specimens (79\%) had positive direct smears, only $28(62 \%)$ were culture positives. We found $\mathrm{KOH}$ preparation to be more sensitive than culture in the detection of superficial fungal infections. Discrepancies between direct microscopic examination and the subsequent culture are well known confirming the requirement of both tests for the diagnosis of superficial mycoses. ${ }^{13}$ In our study, seventeen (38\%) of direct smear positive samples were negative in culture. These results could be due to the lack of viable fungal filaments in the sample due to treatment with anti-fungal agents. There were nine samples which were $\mathrm{KOH}$ negative but culture positive. In these samples we observed that the fungal colonies were arising exactly where the specimens were inoculated. In a similar study done by Das et al. (2007) in 909 patients, $25(2.7 \%)$ were $\mathrm{KOH}$ negative and culture positive. ${ }^{14}$ This may be due to the presence of scanty amounts of organisms and/or possible contamination.

Socio-demographic characteristics of our study population had no significant relationship with SFIs with regard to gender, age, level of education, civil status and work experience. A similar result was also shown by Mokadem et al. (2007) in a study done in Egypt. ${ }^{15}$

This study group had more females (88\%) than males (12\%) due to employment of a higher number of female cleaning workers. Some studies described that females are at a higher risk of having SFIs than males. ${ }^{4}$ However, differences between the sexes with regard to SFIs have not been studied adequately. ${ }^{16}$

Various risk factors were identified for SFIs such as wet work duration per day, age, type of occupation and having a previous infection. ${ }^{15}$ According to the study of Mokadem et al. (2007) wet work duration of 30 to 120 minutes per day is highly significant for causing SFIs among hospital workers who are frequently in contact with water, detergents and cleansers. ${ }^{15}$ In the current study group, those exposed to water, detergents and soil had higher infections (55\%) compared to the less exposed (42\%). However our study showed that there was no statistically significant relationship between the duration of wet work hours per day and SFIs. The reason for this could be due to the small population involved in the study.

Our study also showed that there was no statistically significant relationship between the level of education and the use of safety measures (protective gloves, shoes, clothes) with the transmission of SFIs. However others have claimed that the level of education is inversely related to developing SFIs. ${ }^{17}$ It is known that educated people are aware of SFIs, risk factors and safety measures, thus taking preventive action. ${ }^{15}$ The small sample number could maybe explain the lack of statistical significance with the level of education.

In our study, $58 \%$ of workers $>50$ years of age were infected with SFIs but there was again no statistical significance in this finding. However as the age of our study population was not distributed evenly it is impossible to predict age as a major risk factor among our population. Previous studies have reported controversial results where they encountered that transmission of 
SFIs increases with age. ${ }^{18}$ On the other hand, Das et al. (2007) have highlighted that SFIs were mostly reported among younger groups. ${ }^{19}$

Fifty three percent of the volunteers had SFIs despite having a good attitude and satisfactory practices.

It was interesting to note that $50 \%$ of participants who stated that they use safety measures had SFIs. This may be due to lack of awareness of the correct use of safety measures.

Overall, the study population showed good total attitude (49\%) towards SFIs and satisfactory level of practices $(58 \%)$, whereas knowledge (42\%) was at an unsatisfactory level.

Gaps in knowledge with regard to occupation related safety practices and predisposing conditions may be an important contributing factor to the high proportion of SFIs among this study group. Further it was noticed that most of the participants (71\%) were not aware that they had a SFI until examined by the Clinical Microbiologist. In conclusion, regular examination of this population is recommended because they are at high risk for fungal diseases.

\section{References}

1. Jayathilake J.A.M.S., Tilakaratne W.M., Panagoda G.J. Candidal Onychomycosis - A mini review. Mycologia 2009; 168:165-173. doi: 10.1007/s11046-009-9212-x.

2. Attapattu M.C. A study of tinea capitis in Sri Lanka. J Med Vet Mycol 1989; 27:27-32. doi : http://dx.doi.org/10.1080/02681218980000041

3. Wijesuriya T.M., Weerasekera M.M., Gunasekara T.D.C.P., Kottahachchi J., Fernando S.S.N., Bulugahapitiya U., Prathapan S., Dissanayake M.S.S., Nagahawatha A., Guruge L.D., Ranasinghe K.N.P. Proportion of lower limb fungal foot infections in patients with type 2 diabetes at a tertiary care hospital in Sri Lanka. Indian JEndocrinolMetab 2014 8(1). 63-69 No doi

4. Bassiri-Jahromi S., Khaksari A.A. Epidemiological survey of dermatophytosis in Tehran, Iran, from 2000 to 2005. Indian J Dermatol Venereol Leprol 2009; 75:142-147. doi : http://dx.doi.org/10.4103/0378-6323.48658

5. Kelly B.P. Superficial fungal infections. Pediatric Review 2012; 33:22-23. doi : http://dx.doi.org/10.1542/pir.33-4-e22

6. Shukla D., Renu G., Bhattacharya S.N. Laboratory-based epidemiological study of superficial fungal infections. J Dermatol 2007; 34:248-253. doi : http://dx.doi.org/10.1111/j.1346-8138.2007.00262.x

7. Mahmoudabadi A.Z., Baharea I.Z.A.D.I. Prevalence of cutaneous mycoses among workers. Turk J Med Sci 2011; 41:291-294. doi:10.3906/sag-1003-661

8. Warnock D.W. Fungi. In: Greenwood D, Slack R, Peeuther R, Barer M (eds). Medical Microbiology. Philadelphia: Churchill Livingstone Elsevier, 2007: pp 616-641.

9. Mahmoudabadi A.Z., Zarrin M. Onychomycosis with Aspergillus flavus; a case report from Iran. Pak J Med Sci 2005; 21:497-498. No doi

10. Gianni C., Romano C. Clinical and histological aspects of toenail onychomycosis caused by Aspergillus spp.: 34 cases treated with weekly intermittent terbinafine. Dermatology 2004; 209:104-110. doi : http://dx.doi.org/10.1159/000079593

11. Martínez R.L., Candidosis, a new challenge. Clin Dermatol 2010; 28:178-184. doi : http://dx.doi.org/10.1016/j.clindermatol.2009.12.014 
12. Yehia M.A., El-Ammawi T.S., Al-Mazidi K.M., Abu El-Ela M.A., Al-Ajmi H.S. The spectrum of fungal infections with a special reference to dermatophytoses in the capital area of Kuwait during 2000-2005: a retrospective analysis. Mycopathologia 2010; 169:241-246. doi : http://dx.doi.org/10.1007/s11046-009-9252-2

13. Lefler E., Haim S., Merzbach D. Evaluation of direct microscopic examination versus culture in the diagnosis of superficial fungal infections. Mycoses 1981; 24:102-106. doi :http://dx.doi.org/10.1111/j.1439-0507.1981.tb01841.x

14. Das S., Goyal R., Bhattacharya S.N. Laboratory-based epidemiological study of superficial fungal infections. J Dermatol 2007; 34:248-253. doi : http://dx.doi.org/10.1111/j.1346-8138.2007.00262.x

15. Mokadem S.A., Refat A., Naggar. An intervention epidemiological study of occupational dermatoses at Zagazig University Hospitals. Egyptian Dermatology Online Journal 2007; 3(2):1-23. No doi

16. Meding B. Differences between the sexes with regard to work-related skin disease.

Contact Dermatitis 2000; 43:65-71.

doi : http://dx.doi.org/10.1034/j.1600-0536.2000.043002065.x

17. Sahin I., Kaya D., Parlak A.H., Oksuz S., Behcet M. Dermatophytoses in forestry workers and farmers. Mycoses 2005; 48:260-264. doi : http://dx.doi.org/10.1111/j.1439-0507.2005.01135.x

18. Meding B., Lantto R., Lindahi G. Occupational Skin Disease in Sweden - A 12 years follow up. Contact Dermatitis 2005; 53:308-314.

doi : http://dx.doi.org/10.1111/j.0105-1873.2005.00731.x

19. Das K., Basak S., Ray S. A study on superficial fungal infection from West Bengal; A brief report. J Life Sci 2009; 1:51-55. No doi 